\title{
MATHEMATICAL MODEL OF THE MECHANICAL PROPERTIES OF TI-ALLOYED HYPOEUTECTIC CAST IRON FOR MIXER BLADES
}

\author{
Sergei Kharchenko \\ Department of Technological Systems ${ }^{1}$ \\ kharchenko_mtf@ukr.net \\ Andriy Barsuk \\ Department of Technological Systems ${ }^{1}$ \\ texncentr@gmail.com \\ Nurlana Karimova \\ Department of Engineering and Applied Sciences \\ Azerbaijan State University of Economics(UNEC) \\ 6 Istiglyaliyat str., Baku, Azerbaijan, AZ 1001 \\ kerimova-nurlana@mail.ru \\ Nanka Alexander ${ }^{1}$ \\ nanka-1@i.ua \\ Yevhen Pelypenko \\ Department of Car and Tractor Industry ${ }^{2}$ \\ pelipenkoeugene@gmail.com \\ Vadim Shevtsov \\ Department of Car and Tractor Industry ${ }^{2}$ \\ shevtsovvadim@ukr.net \\ Ivan Morozov \\ Department of Agricultural Machines ${ }^{1}$ \\ ivanmorozov1937@gmail.com \\ Vladimir Morozov \\ Department of Economics and Marketing ${ }^{1}$ \\ morozov.ukraine@gmail.com
}

${ }^{1}$ Kharkiv Petro Vasylenko National Technical University of Agriculture 44 Alchevskykh str., Kharkiv, Ukraine, 61022

${ }^{2}$ National Technical University «Kharkiv Polytechnic Institute»

2 Kyrpychova str., Kharkiv, Ukraine, 61002

\footnotetext{
Abstract

The object of research is hypoeutectic cast iron intended for cast parts operating under abrasive friction conditions. Such parts are mixer blades, the operational properties of which include durability, assessed by abrasion resistance and strength. To give the blades such properties, cast irons, which are materials of the blades, are alloyed with elements that contribute to the formation of carbides of various compositions. The main problem that impedes the targeted selection of materials for mixer blades or finished blades from different materials or different chemical composition is the lack of substantiated selection criteria. If the shipment is carried out only with the provision of data on the chemical composition of the alloy, it is necessary to be able to evaluate the expected mechanical properties, in particular abrasion resistance and strength.

Using the methods of regression analysis, a mathematical model has been obtained that includes two regression equations, which allows for a targeted selection of the chemical composition that provides the maximum possible value of mechanical properties - ultimate strength and coefficient of wear resistance. Optimization of the chemical composition, carried out according to this model,
} 
made it possible to determine the following chemical composition: $\mathrm{C}=2.94 \%, \mathrm{C}_{e q}=3.3 \%, \mathrm{Ti}=1.56 \%$, providing the maximum ultimate strength $\sigma_{b}=391 \mathrm{MPa} ; \mathrm{C}=2.78 \%, \mathrm{C}_{e q}=3.14 \%, \mathrm{Ti}=1.61 \%$, providing a maximum wear resistance coefficient $K_{w r}=12 \%$.

In the case of priority of the strength criterion, the calculated optimal chemical composition makes it possible to reduce the mass-dimensional characteristics of the mixing units of the mixers.

A procedure is proposed for using this model to select a batch of blades with the expected best performance properties.

Keywords: mixer blades, wear resistance coefficient, ultimate strength, hypoeutectic cast iron, alloying.

DOI: $10.21303 / 2461-4262.2021 .001830$

\section{Introduction}

Improving the performance of mixers used in agriculture puts forward a number of specific design requirements. They relate to the need to satisfy several requirements at once, and sometimes the opposite. It can be high productivity and high reliability of the most loaded parts and assemblies while ensuring the specified requirements for the quality of the mixed product. It is also important today to meet the requirements for reducing the energy consumption of mixers, which is associated with the need to reduce the mass-dimensional characteristics while maintaining high efficiency at the same loads on the working bodies. Some of the most important parts for which these requirements must be met are the mixing elements, in particular the mixer blades. The available literature data make it possible to identify typical directions for improving the designs and materials of mixer blades.

In [1] the actual problem of increasing the service life of the used paddle mixers is considered. The existing methods of ensuring the wear resistance of mixer blades are presented, their advantages and disadvantages are indicated. The results of laboratory studies of the wear rate of thermal gas coatings from various powder mixtures of the Ni-Cr-B-Si system under abrasive wear conditions are presented. The results of operational tests of prototypes under conditions of corrosion-abrasive wear during the operation of a paddle mixer are presented. The composition of the powder mixture has been developed to ensure the maximum wear resistance of the mixer blades.

In [2] it is indicated that the use of drum mixers allows to obtain feed mixtures of high uniformity, eliminating the phenomenon of segregation and the formation of «dead» zones. The presence of radial vanes inside the chamber distributes the mixing body and increases surface flows, which improves the redistribution of material along the mixing axis.

In [3], the problem of obtaining mixtures of bulk materials, which is relevant for various industries, is considered. The considered drum mixers are characterized by a negligible effect on the mixed material and can be used in technological schemes that require minimal particle damage. The presented mixer designs have small dimensions and low energy consumption. They provide good smoothing of complex input fluctuations by means of volumetric metering. The time of the mixing process in them does not exceed a few minutes, and various volumetric compositions provide good quality.

The described design solutions are based on general engineering approaches and require improvement with the use of modern modeling and design tools, which allow at the development stage to take into account many important factors affecting performance. The operating conditions of the blades during operation make it possible to consider them in general as a typical part operating on abrasive friction, regardless of the media to be mixed. From this position, it is possible to analyze the main research tools used for such typical parts, conditions and indicators of their operation. For example, [4] used discrete element modeling (DEM), which is rapidly spreading as a modeling tool for analyzing processes associated with solid particles. And also to meet the technological needs of various aspects of the pharmaceutical, food and detergent processing industries. Examples include evaluating parameters that are difficult to measure or evaluate experimentally (e. g., internal flow fields and mixing patterns), and facilitate the scaling of particulate processing from laboratory to pilot plant.

In [5], the flow field in a cylindrical container driven by an impeller with flat blades was considered. The studies were performed using particle imaging velocimetry (PIV). The results showed that vortices were formed at the ends of the blades that rotated with them. As the blades moved closer to the wall, the vortices interacted with the induced boundary layer on the wall, enhancing both vorticity regions. Stirring was evaluated using zero-mass convection particles by numerically integrating experimentally obtained velocity fields. Mixing data confirmed the location of high 
mixing areas and barriers shown by LCS analysis. The results showed that mixing increased in the region described by the blade movement when the blade was positioned close to the cylinder wall.

[6] uses a discrete element method to simulate the mixing process of solids in a horizontal ribbon mixer with a double U-shaped vessel. The mixing index, that is, the so-called Lacy index, is adopted to assess the mixing quality of the particles. The effect of operating and geometric parameters, including initial loading, particle size, impeller speed, and internal blades, on particle mixing quality was investigated. The results show that the initial load and the impeller speed have a significant effect on the mixing quality of the particles, while the other two parameters have a relatively small effect. Moreover, the influence of each parameter on the mixing quality was explained by using the components of the relative velocity between the centroids of the particles after the collision. This ribbon blender provides much more intense relative particle motion in the vertical direction than in the axial and lateral directions.

In [7], a study of mixing in industrial mixers is carried out using the Advanced DEM-CFD method. It has been found that rotation speed, fill level, fluid viscosity and blade tilt can significantly affect mixing efficiency. Due to the significantly enhanced convective particle motion, the higher rotation speed provides a more efficient mixing process. Fewer particles inside the vessel show better mixing performance due to the increased diffusion motion of the particles. Decreasing the viscosity of the fluid or increasing the angle of the blade can also lead to more efficient mixing in the dominant diffusion mode.

In [8], methods of analytical construction of the profile of the mixer rotor blades are considered, as well as mathematical modeling of their work on moving and mixing bulk materials on a conveyor to increase the efficiency of the mixing process of raw materials and optimize its operating costs. The rational parameters and geometric characteristics of the profile of the rotor mixer blades were determined, which contribute to improving the mixing quality of the metallurgical charge transported on the conveyor belt.

In the study [9], a soft metal with low wear resistance (6000 series aluminum) was used to minimize the operating time at the maximum wear rate of the blades. Recommendations were developed for the use of different types of blade configurations, as well as their location relative to each other.

In [10], general information is provided on the technology of preparation of feed and feed mixtures, in which various machines, units and technological complexes are used. The choice of technological equipment for the preparation of feed for feeding largely determines not only the quantity and quality of products obtained from animals and poultry, but also the health of these animals.

Based on the results of the analysis [1-10], it can be concluded that the reasonable choice of the material of the blades is not represented properly, which is especially important in the design of mixers. Mixer blades during operation are in a state of abrasive friction and their durability is determined by the quality of the alloy from which they are made. The use of alloy steels for these purposes requires the implementation of a complex of technological processes aimed at ensuring the specified strength characteristics of the working surface. Such characteristics are obtained, for example, by promising technologies of nitriding [11] or boriding [12] and are estimated by the surface hardness and the depth of the diffusion layer. Requirements to reduce the cost of manufacturing blades while ensuring high operational properties necessitate the search for the most suitable alloy. Such alloys can be cast irons alloyed with various elements: $\mathrm{Cr}, \mathrm{Ni}, \mathrm{Cu}, \mathrm{Ti}, \mathrm{V}$, which impart the required properties to cast iron [13-15].

Manufacturing blades from white cast iron may be preferred over alloy steels. It is especially important to choose the chemical composition of white cast iron, usually alloyed with boron, in order to impart high wear-resistant properties. However, one can't be limited only by the choice of boron as an alloying element. Known production data on the effective use of titanium as an alloying element, used either in conjunction with boron [16], or independently [17]. This choice is justified by the fact that when alloying low-carbon hypoeutectic cast iron, its structure consists mainly of decomposition products of austenite, ledeburite, inclusions of titanium carbide and acicular cementite (Fig. 1) [17]. Such a structure provides a lower value of hardness compared to cast iron alloyed with boron, but a comparable wear resistance coefficient, estimated by determining the loss of mass during friction by comparison with a reference sample. 


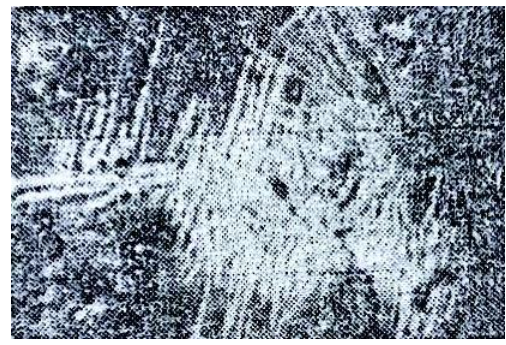

Fig. 1. Microstructure of cast iron with carbon content $<2.5 \%$, alloyed with titanium, $\times 500$

Such cast irons can be smelted in induction furnaces, allowing:

- quickly introduce and distribute alloying materials [18];

- overheat the alloy to temperatures that ensure the formation of a given microstructure [19-21];

- regulate the temperature and slag conditions, ensuring the stability of the chemical composition of the alloy [22].

However, the availability of separate production data on the chemical composition of the alloy, its mechanical properties and the peculiarities of the technology of its production, presented in [11-22], does not make it possible to systematically assess the influence of the main factors in the formation of the microstructure of cast iron on its performance properties. These factors are carbon and carbon equivalent, which includes not only carbon, but also silicon and manganese. These elements affect the position of the eutectic point on the Fe-C phase diagram and therefore affect the formation of the final structure at a given alloy cooling rate. Taking into account the fact that alloying with titanium leads to structural changes, it is necessary to consider the combined effect of carbon, carbon equivalent, and titanium on the properties of cast iron. Taking as a basis two main indicators of properties that determine the serviceability of cast iron operating under abrasive friction - the wear resistance coefficient and the tensile strength - it is necessary to build a mathematical model that allows to reasonably choose the material at the stage of designing the mixing elements of mixers. Such mathematical models belong to the class of «composition - properties» models [23] and in industrial experiments are constructed by the least squares method according to the data of a passive experiment, in particular, using artificial orthogonalization [24]. This article is devoted to the construction of such models, which describes the results of research aimed at solving the problem associated with the lack of the ability to systematically assess the influence of the main factors in the formation of the microstructure of cast iron on its operational properties.

\section{Materials and Methods}

A mathematical model was built that includes two regression equations:

$$
\sigma_{b}=f_{1}\left(\mathrm{C} ; \mathrm{C}_{e q} ; \mathrm{Ti}\right)
$$

and

$$
K_{w r}=f_{2}\left(\mathrm{C} ; \mathrm{C}_{e q} ; \mathrm{Ti}\right)
$$

in which the following designations are accepted: $\sigma_{b}$ - tensile strength, $\mathrm{MPa}, K_{w r}-$ wear resistance coefficient, $\%, \mathrm{C}-$ carbon content in the alloy, $\%, \mathrm{C}_{e q}-$ carbon equivalent, $\mathrm{Ti}-$ titanium content in the alloy, \%. These equations were considered as a development of the models described in [25], which did not take into account the effect of carbon, as one of the main elements affecting both the ultimate strength and the coefficient of wear resistance. The first is due to the fact that an increase in the carbon content leads to the development of the graphitization process, as a result of which graphite is formed in the microstructure, which plays the role of «notches» in the continuous matrix of cast iron, thereby reducing the mechanical strength. The second is associated with the fact that carbon participates in the formation of carbides of different compositions, imparting wear 
resistance properties to the surface. In this case, as noted above, the relative position of carbon and carbon equivalent on the $\mathrm{Fe}-\mathrm{C}$ phase diagram are factors that significantly affect the formation of the microstructure, and hence the properties of cast iron.

To construct a mathematical model, a sample of production data given in [26] (Table 1) was used.

Table 1

Initial data sample [26]

\begin{tabular}{|c|c|c|c|c|c|c|}
\hline \multicolumn{5}{|c|}{ Chemical composition, $\%$} & \multicolumn{2}{|c|}{ Mechanical properties } \\
\hline $\mathbf{C}$ & $\mathbf{S i}$ & Mn & $\mathrm{C}_{e q}^{*}$ & Ti & $\sigma_{b}, \mathrm{~kg} / \mathrm{mm}^{2}$ & $K_{\text {zor }}, \%$ \\
\hline 2.25 & 1.31 & 0.95 & 2.615 & 0.32 & 45.2 & 6.2 \\
\hline 2.37 & 1.4 & 0.99 & 2.76 & 0.63 & 44.4 & 11.54 \\
\hline 2.26 & 1.03 & 1.01 & 2.539 & 0.94 & 38.8 & 9.57 \\
\hline 2.21 & 1.53 & 0.95 & 2.641 & 1.69 & 30 & 9.44 \\
\hline 2.4 & 1.16 & 1.14 & 2.714 & 2.1 & 31.1 & 10.8 \\
\hline 2.68 & 1.08 & 0.6 & 2.986 & 0.37 & 28.4 & 8.19 \\
\hline 2.69 & 0.93 & 1.07 & 2.937 & 0.75 & 27.4 & 9.7 \\
\hline 2.53 & 1.5 & 1.02 & 2.949 & 1.26 & 36.2 & 12.27 \\
\hline 2.73 & 1.1 & 1.21 & 3.024 & 2.94 & 27.9 & 9.7 \\
\hline 3.13 & 1.6 & 0.78 & 3.587 & 0.28 & 20.1 & 8.26 \\
\hline 3.34 & 1.4 & 1.1 & 3.727 & 0.73 & 24.5 & 11.07 \\
\hline 3.24 & 1.4 & 0.98 & 3.631 & 1.54 & 33.9 & 9.19 \\
\hline 3.34 & 1.72 & 0.98 & 3.827 & 2.5 & 17.8 & 8.07 \\
\hline
\end{tabular}

Note: $*-C_{e q}$ was calculated by the formula: $C_{e q}=0.3 \mathrm{Si}-0.03 \mathrm{Mn}, \%$

The values of the input variables were normalized according to the formulas:

$$
x_{i}=\frac{x_{i}^{*}-\overline{x_{i}}}{I_{i}},
$$

where $x_{i}$ - normalized value of the $i$-th independent variable ( $i=1$ for $\mathrm{C}, i=2$ for $\mathrm{C}_{e q}, i=1$ for Ti), $x_{i}^{*}$ - natural value of the $i$-th independent variable, $\%, \overline{x_{i}}-$ mean value of the $i$-th independent variable variable, $\%, I_{i}$ - interval of variation of the values of the $i$-th independent variable.

Table 2 shows the intervals of variation of independent variables, and Table 3 shows the results of calculations of their normalized values

The general form of the regression equations was taken as polynomial:

$$
y_{j}=a_{0 j}+a_{1 j} x_{1 j}+a_{2 j} x_{2 j}+a_{3 j} x_{3 j}+a_{4 j} x_{1 j}^{2}+a_{5 j} x_{2 j}^{2}+a_{6 j} x_{3 j}^{2}+a_{7 j} x_{1 j} x_{2 j}+a_{8 j} x_{1 j} x_{3 j}+a_{9 j} x_{2 j} x_{3 j},
$$

where $j$-index of the output variable: $j=1$ for $\sigma_{b}, j=2$ for $K_{w}$.

Table 2

Variation of independent variables

\begin{tabular}{cccc}
\hline Standardization parameters & $\mathbf{C ,} \mathbf{\%}$ & $\mathbf{C}_{\text {eq }}, \mathbf{\%}$ & $\mathbf{T i}, \mathbf{\%}$ \\
\hline Lower limit of the interval, \% & 2.21 & 2.539 & 0.28 \\
The upper limit of the interval, \% & 3.34 & 3.827 & 2.94 \\
Average value, $\%$ & 2.775 & 3.183 & 1.61 \\
Variation interval, \% & 0.565 & 0.644 & 1.33
\end{tabular}


Table 3

Results of calculating the normalized values of independent variables

\begin{tabular}{cccccc}
\hline $\mathbf{C} \boldsymbol{\%}$ & $\boldsymbol{x}_{\mathbf{1}}$ & $\mathbf{C}_{\boldsymbol{e q}} \boldsymbol{\%} \boldsymbol{\%}$ & $\boldsymbol{x}_{\mathbf{2}}$ & $\mathbf{T i} \boldsymbol{\%}$ & $\boldsymbol{x}_{\mathbf{3}}$ \\
\hline 2.25 & -0.929 & 2.615 & -0.882 & 0.32 & -0.97 \\
2.37 & -0.717 & 2.76 & -0.657 & 0.63 & -0.737 \\
2.26 & -0.912 & 2.539 & -1 & 0.94 & -0.504 \\
2.21 & -1 & 2.641 & -0.842 & 1.69 & 0.0602 \\
2.4 & -0.664 & 2.714 & -0.728 & 2.1 & 0.3684 \\
2.68 & -0.168 & 2.986 & -0.306 & 0.37 & -0.932 \\
2.69 & -0.15 & 2.937 & -0.382 & 0.75 & -0.647 \\
2.53 & -0.434 & 2.949 & -0.363 & 1.26 & -0.263 \\
2.73 & -0.08 & 3.024 & -0.247 & 2.94 & 1 \\
3.13 & 0.6283 & 3.587 & 0.6273 & 0.28 & -1 \\
3.34 & 1 & 3.727 & 0.8447 & 0.73 & -0.662 \\
3.24 & 0.823 & 3.631 & 0.6957 & 1.54 & -0.053 \\
3.34 & 1 & 3.827 & & 2.5 & 0.6692
\end{tabular}

The coefficients of equations (2) were estimated by the least squares method:

$$
A=\left(F^{T} F\right)^{-1} F^{T} Y
$$

where $F$ - matrix of the experimental design, $F^{T}$ - transposed matrix of the experimental design, $\left(F^{T} F\right)^{-1}=C$ - variance matrix, $Y$ - matrix of output variables $\left(\sigma_{b}\right.$ and $K_{\varpi r}$, depending on the output variable for which the regression equation is constructed), $A$ - matrix of estimates of the coefficients of the regression equations.

To estimate the confidence interval for $\sigma_{b}\left(y_{1}\right)$ and $K_{w r}\left(y_{2}\right)$, the lower and upper bounds of the output variables were calculated:

$$
\begin{aligned}
& y^{-}=y_{\text {calc }}-\frac{t_{c r} s}{\sqrt{N}}, \\
& y^{+}=y_{\text {calc }}+\frac{t_{c r} s}{\sqrt{N}},
\end{aligned}
$$

where $s$ - standard deviation, determined from the formula:

$$
s=\sqrt{\frac{S_{R}^{2}}{\varphi}},
$$

where $S_{R}^{2}=\sum_{i=1}^{13}\left(y_{\text {calc } i}-y_{\text {exp } i}\right)^{2}-$ sum of the squares of the deviations of the experimental values of the output variables from the calculated ones obtained by the regression equations, $\varphi=N-(k+1)-$ the number of degrees of freedom, $N$ - the number of experiments $(N=13), k$ - the number of estimated coefficients for independent variables $(k=9), t_{c r}$ - critical value of Student's distribution for a confidence level of $95 \%$ and the number of degrees of freedom $\varphi=3$.

The validation of the mathematical model was checked by checking the degree of correspondence of each regression equation to the experimental data. And also by assessing the hit of the actual experimental values in the confidence interval with a confidence level of $95 \%$.

\section{Results and discussion}

The mathematical model is a system of two regression equations: $\sigma_{b}=y_{1}=f_{1}\left(x_{1}, x_{2}, x_{3}\right)$ and $K_{w r}=y_{2}=f_{2}\left(x_{1}, x_{2}, x_{3}\right)$ and has the form: 


$$
\begin{aligned}
& y_{1}=365.0805+565.9379 x_{1}-613.556 x_{2}-20.5485 x_{3}-3318.2 x_{1}^{2}-4182.84 x_{2}^{2}- \\
& -50.0652 x_{3}^{2}+7411.136 x_{1} x_{2}+100.7474 x_{1} x_{3}-69.1735 x_{2} x_{3}, \\
& y_{2}=12.08145+1.917424 x_{1}-2.09456 x_{2}-0.39929 x_{3}-13.2789 x_{1}^{2}-14.3292 x_{2}^{2}- \\
& -3.20145 x_{3}^{2}+25.76207 x_{1} x_{2}+4.497585 x_{1} x_{3}-5.47818 x_{2} x_{3} .
\end{aligned}
$$

Tables 4, $\mathbf{5}$ show the results of statistical processing of the data obtained to validate the mathematical model. Table 4 shows that out of 13 experimental points, only 3 points fell outside the confidence interval. This allows to consider the model suitable for predicting the value of the ultimate strength, taking into account the fact that for 10 estimated coefficients, only 13 experimental points were used in a passive experiment (Table 5).

\section{Table 4}

Equation validation evaluation $\sigma_{b}=y_{1}=f_{1}\left(x_{1}, x_{2}, x_{3}\right)$

\begin{tabular}{cccccc}
\hline $\boldsymbol{y}_{\mathbf{1} \text { calc }}, \mathbf{M P a}$ & $\left(\boldsymbol{y}_{\mathbf{1} \text { calc }}-\boldsymbol{y}_{\mathbf{1 e x p}}\right), \mathbf{M P a}$ & $\left(\boldsymbol{y}_{\text {1 calc }}-\boldsymbol{y}_{\mathbf{1 e x p}}\right)^{\mathbf{2}}, \mathbf{M P a}^{\mathbf{2}}$ & $\boldsymbol{y}_{\mathbf{1}}^{-}, \mathbf{M P a}$ & $\boldsymbol{y}_{\mathbf{1}}^{+}, \mathbf{M P a}$ & $\boldsymbol{y}_{\mathbf{1 e x p}}, \mathbf{M P a}$ \\
\hline 452 & 0 & 0 & 431 & 473 & 452 \\
407 & -37 & 1369 & 386 & 428 & 444 \\
380 & -8 & 64 & 359 & 401 & 388 \\
323 & 23 & 529 & 302 & 344 & 300 \\
322 & 11 & 121 & 301 & 343 & 311 \\
346 & 62 & 3844 & 325 & 367 & 284 \\
258 & -16 & 256 & 237 & 279 & 274 \\
352 & -10 & 100 & 331 & 373 & 362 \\
263 & -16 & 256 & 242 & 284 & 279 \\
191 & -10 & 100 & 170 & 212 & 201 \\
237 & -8 & 64 & 216 & 258 & 245 \\
339 & 0 & 0 & 318 & 360 & 339 \\
190 & 12 & 144 & 169 & 211 & 178
\end{tabular}

\begin{tabular}{|c|c|c|c|c|c|}
\hline$y_{2 \text { calc }}, \%$ & $\left(y_{2 \text { calc }}-y_{2 \exp }\right), \%$ & $\left(y_{2 \text { calc }}-y_{2 e x p}\right)^{2}, \%^{2}$ & $y_{2}, \%$ & $y_{2}^{+}, \%$ & $y_{2 \exp }, \%$ \\
\hline 7 & 0.8 & 0.64 & 6 & 8 & 6.2 \\
\hline 9 & -2.54 & 6.4516 & 8 & 10 & 11.54 \\
\hline 9 & -0.57 & 0.3249 & 8 & 10 & 9.57 \\
\hline 10 & 0.56 & 0.3136 & 9 & 11 & 9.44 \\
\hline 11 & 0.2 & 0.04 & 10 & 12 & 10.8 \\
\hline 9 & 0.81 & 0.6561 & 8 & 10 & 8.19 \\
\hline 10 & 0.3 & 0.09 & 9 & 11 & 9.7 \\
\hline 12 & -0.27 & 0.0729 & 11 & 13 & 12.27 \\
\hline 9 & -0.7 & 0.49 & 8 & 10 & 9.7 \\
\hline 9 & 0.74 & 0.5476 & 8 & 10 & 8.26 \\
\hline 9 & -2.07 & 4.2849 & 8 & 10 & 11.07 \\
\hline 11 & 1.81 & 3.2761 & 10 & 12 & 9.19 \\
\hline 8 & -0.07 & 0.0049 & 7 & 9 & 8.07 \\
\hline
\end{tabular}

Note: $s=23.88689 \mathrm{MPa}, \frac{t_{c r} s}{\sqrt{N}}=21.1 \mathrm{MPa}$

Table 5

Equation validation evaluation $K_{w r}=y_{2}=f_{2}\left(x_{1}, x_{2}, x_{3}\right)$

Note: $s=1.196991 \%, \frac{t_{c r} s}{\sqrt{N}}=1.1 \%$ 
Table 5 shows that out of 13 experimental points, only 3 points fell outside the confidence interval, so the conclusion regarding the predictive capabilities of this model is the same as for the model $\sigma_{b}=y_{1}=f_{1}\left(x_{1}, x_{2}, x_{3}\right)$.

The visual results of the validation of the mathematical model are shown in Fig. $2,3$.

For practical application of the obtained mathematical models (7), (8), their normalized form is reduced to natural form:

$$
\begin{aligned}
& y_{1}=365.0805+565.9379 \frac{x_{1}-2.775}{0.565}-613.556 \frac{x_{2}-3.183}{0.644}-20.5485 \frac{x_{3}-1.61}{1.33}- \\
& -3318.2\left(\frac{x_{1}-2.775}{0.565}\right)^{2}-4182.84\left(\frac{x_{2}-3.183}{0.644}\right)^{2}-50.0652\left(\frac{x_{3}-1.61}{1.33}\right)^{2}+ \\
& +7411.136\left(\frac{x_{1}-2.775}{0.565}\right)\left(\frac{x_{2}-3.183}{0.644}\right)+100.7474\left(\frac{x_{1}-2.775}{0.565}\right)\left(\frac{x_{3}-1.61}{1.33}\right)- \\
& -69.1735\left(\frac{x_{2}-3.183}{0.644}\right)\left(\frac{x_{3}-1.61}{1.33}\right) \text {, } \\
& y_{2}=12.08145+1.917424 \frac{x_{1}-2.775}{0.565}-2.09456 \frac{x_{2}-3.183}{0.644}-0.39929 \frac{x_{3}-1.61}{1.33}- \\
& -13.2789\left(\frac{x_{1}-2.775}{0.565}\right)^{2}-14.3292\left(\frac{x_{2}-3.183}{0.644}\right)^{2}-3.20145\left(\frac{x_{3}-1.61}{1.33}\right)^{2}+ \\
& +25.76207\left(\frac{x_{1}-2.775}{0.565}\right)\left(\frac{x_{2}-3.183}{0.644}\right)+4.497585\left(\frac{x_{1}-2.775}{0.565}\right)\left(\frac{x_{3}-1.61}{1.33}\right)- \\
& -5.47818\left(\frac{x_{2}-3.183}{0.644}\right)\left(\frac{x_{3}-1.61}{1.33}\right) \text {. }
\end{aligned}
$$

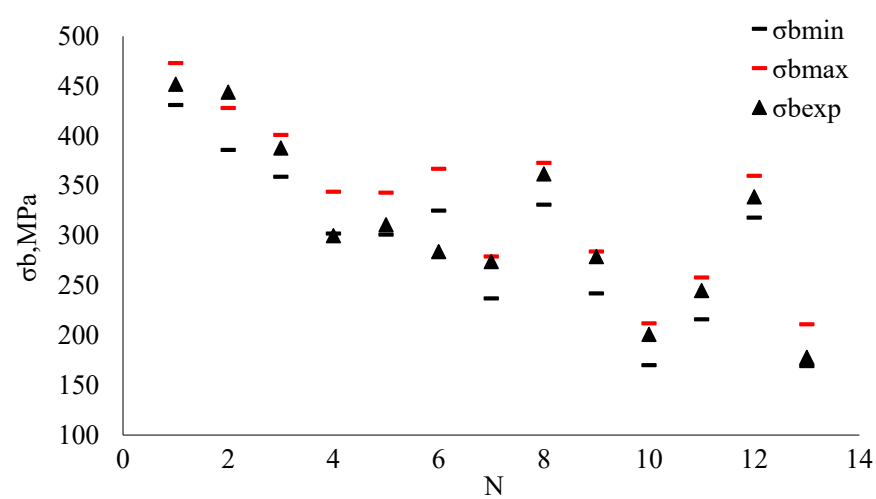

Fig. 2. Regression equation validation results $\sigma_{b}=y_{1}=f_{1}\left(x_{1}, x_{2}, x_{3}\right)$

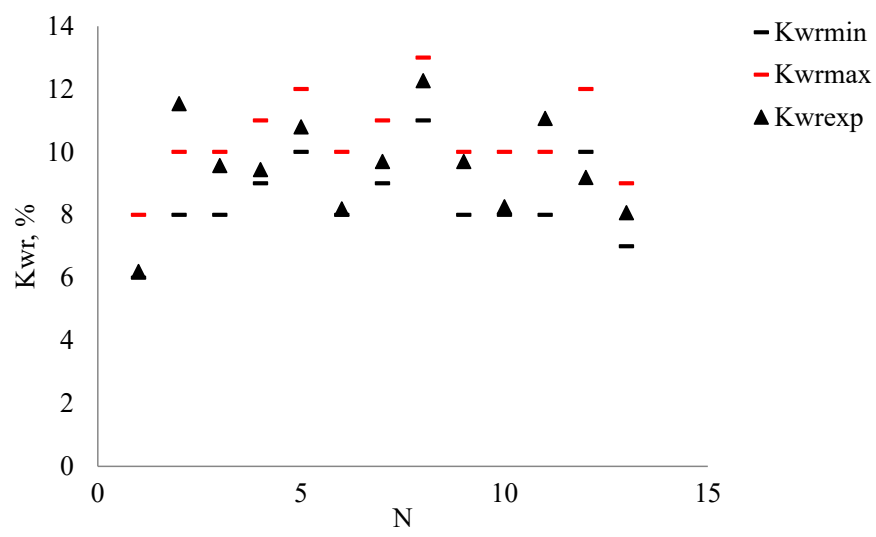

Fig. 3. Regression equation validation results $K_{\text {wr }}=y_{2}=f_{2}\left(x_{1}, x_{2}, x_{3}\right)$ 
The resulting models can be used in almost two ways.

Method 1 «design».

This method is used at the design stage of the mixer assemblies and consists in the fact that the designer assigns the optimal chemical composition of cast iron for the blades according to the criterion of maximum strength, which must be provided at the stage of blades delivery. The choice of just such an optimality criterion is justified by the fact that an increase in the ultimate strength makes it possible to reduce the mass and size characteristics of the blades, which directly follows from the condition:

$$
\left[\sigma_{b 1}\right] S_{1}=n\left[\sigma_{b 1}\right] S_{2} \rightarrow S_{2}=\frac{S_{1}}{n}
$$

where $n$ - ratio of the tensile strength of the chemically optimized cast iron ( $\left.\left[\sigma_{b 2}\right], \mathrm{MPa}\right)$ to the tensile strength of the chemically-optimized cast iron ( $\left.\left[\sigma_{b 1}\right], \mathrm{MPa}\right), n=\left[\sigma_{b 2}\right] /\left[\sigma_{b 1}\right], S_{1}, S_{2}-$ working area section of a blade of a typical design and an optimized design, respectively, $\mathrm{m}^{2}$.

The optimal chemical composition is found from the condition:

$$
\frac{\partial y_{1}}{\partial x_{i}}=0, \quad y_{1} \rightarrow \max
$$

When choosing the wear resistance coefficient as a criterion for optimizing the coefficient of wear, the conditions for determining the optimal chemical composition have a similar structure in structure:

$$
\frac{\partial y_{2}}{\partial x_{i}}=0, y_{2} \rightarrow \max
$$

Table 6 shows the results of calculating the optimal chemical composition and the expected optimal indicators of mechanical properties.

Table 6

The results of calculating the optimal chemical composition and the expected optimal indicators of mechanical properties

\begin{tabular}{cccccccc}
\hline \multicolumn{2}{c}{$\begin{array}{c}\text { Optimal chemical composition } \\
\text { in standardized form, } \%\end{array}$} & \multicolumn{2}{c}{$\begin{array}{c}\text { Optimal chemical composition } \\
\text { in natural form, } \%\end{array}$} & \multicolumn{2}{c}{$\begin{array}{c}\text { Optimal mechanical } \\
\text { properties }\end{array}$} \\
\hline $\boldsymbol{x}_{\mathbf{1}}$ & $\boldsymbol{x}_{\mathbf{2}}$ & $\boldsymbol{x}_{\mathbf{3}}$ & $\mathbf{C}$ & $\mathbf{C}_{\boldsymbol{e q}}$ & $\mathbf{T i}$ & $\boldsymbol{\sigma}_{b}, \mathbf{M P a}$ & $\boldsymbol{K}_{w r}, \%$ \\
\hline 0.294 & 0.188 & -0.039 & 2.94 & 3.3 & 1.56 & 391 & - \\
0.01 & -0.064 & -0.0006 & 2.78 & 3.14 & 1.61 & - & 12
\end{tabular}

Table 6 shows that the optimal chemical composition for one mechanical property does not correspond to the optimal chemical composition for another mechanical property, although they are close. Therefore, when choosing the ultimate strength as a priority property, the chemical composition $\mathrm{C}=2.94 \%, \mathrm{C}_{e q}=3.3 \%, \mathrm{Ti}=1.56 \%$ should be assigned. Substitution of these values into equation (10) gives the maximum indicator of the wear resistance coefficient $K_{w r}=12 \%$, which indicates the possibility of varying the optimal chemical composition, setting its range: $\mathrm{C}=(2.78-2.94) \%, \mathrm{C}_{e q}=(3.14-3.3) \%, \mathrm{Ti}=(1.56-1.61) \%$. However, this conclusion is of a particular nature and is not unambiguous in the general case.

Method 2 «operational».

This method is used if, during operation, it becomes necessary to replace worn out blades and manufacturers offer different batches that differ in the chemical composition of cast iron. In this case, it is necessary to set the operational requirements for the mechanical properties in the form of ranges $\sigma_{b} \geq\left[\sigma_{b}\right], K_{w r} \geq\left[K_{w r}\right]$, where $\left[\sigma_{b}\right],\left[K_{w r}\right]$ is the minimum required guaranteed value 
of the ultimate strength and wear resistance coefficient, respectively. The batch should be chosen that ensures that both of these conditions are met. For example, manufacturers offer 10 batches of blades, different in chemical composition (Table 7). It is necessary to select those parties that ensure the simultaneous fulfillment of the following conditions: $\sigma_{b} \geq 300 \mathrm{MPa}, K_{w r} \geq 10 \%$. An example of a solution is illustrated in Table 7, in which the last two columns show calculations using mathematical models (7), (8) (in normalized form) or (9), (10) (in kind).

Table 7

An example of the practical application of a mathematical model to select a batch of blades that meets the selected criteria

\begin{tabular}{ccccccccccc}
\hline \multirow{2}{*}{ Series } & \multicolumn{6}{c}{ Chemical composition in natural form, \% } & \multicolumn{2}{c}{ Chemical composition in standardized form } & \multicolumn{2}{c}{ Mechanical properties } \\
\cline { 2 - 11 } & $\mathbf{C}$ & $\mathbf{S i}$ & $\mathbf{M n}$ & $\mathbf{C}_{\boldsymbol{e q}}$ & $\mathbf{T i}$ & $\boldsymbol{x}_{\mathbf{1}}$ & $\boldsymbol{x}_{\mathbf{2}}$ & $\boldsymbol{x}_{\mathbf{3}}$ & $\boldsymbol{\sigma}_{\boldsymbol{b}}, \mathbf{M P a}$ & $\boldsymbol{K}_{\text {zrr }}, \boldsymbol{\%}$ \\
\hline 1 & 2.5 & 0.95 & 0.6 & 2.767 & 0.8 & -0.487 & -0.646 & -0.609 & 281 & 9.7 \\
$\mathbf{2}$ & $\mathbf{2 . 9}$ & $\mathbf{1 . 1}$ & $\mathbf{0 . 6}$ & 3.212 & $\mathbf{0 . 8}$ & 0.221 & 0.045 & -0.609 & $\mathbf{3 4 8}$ & $\mathbf{1 0 . 6}$ \\
3 & 3.1 & 1.2 & 0.9 & 3.433 & 0.3 & 0.575 & 0.388 & -0.985 & 320 & 8.4 \\
4 & 3 & 1.6 & 0.9 & 3.453 & 2.9 & 0.398 & 0.419 & 0.97 & 253 & 7.8 \\
5 & 2.95 & 1.4 & 0.8 & 3.346 & 2.9 & 0.31 & 0.253 & 0.97 & 326 & 8.6 \\
6 & 2.4 & 1.4 & 0.8 & 2.796 & 2.85 & -0.664 & -0.6 & 0.932 & 256 & 8.4 \\
7 & 2.4 & 1.2 & 0.8 & 2.736 & 2.85 & -0.664 & -0.694 & 0.932 & 272 & 5.4 \\
8 & 2.5 & 0.95 & 0.8 & 2.761 & 2 & -0.487 & -0.655 & 0.293 & 262 & 10.4 \\
9 & 2.7 & 0.95 & 1 & 2.955 & 2 & -0.133 & -0.354 & 0.293 & 266 & 11.2 \\
10 & 3.2 & 1.5 & 1 & 3.62 & 2.9 & 0.752 & 0.679 & 0.97 & 315 & 7.7
\end{tabular}

Table 7 shows that only series No. 2 meets both conditions. It is this batch that should be taken from the supplier.

\section{Conclusions}

The obtained mathematical model in the form of two regression equations $\sigma_{b}=f_{1}(\mathrm{C} ; \mathrm{C} e q ; \mathrm{Ti})$ and $K_{w r}=f_{2}\left(\mathrm{C} ; \mathrm{C}_{e q} ; \mathrm{Ti}\right)$ makes it possible to carry out a targeted choice of the chemical composition that provides the maximum possible value of mechanical properties - ultimate strength and wear resistance coefficient. The optimization of the chemical composition, carried out according to this model, made it possible to determine the following chemical composition:

$-\mathrm{C}=2.94 \%, \mathrm{C}_{e q}=3.3 \%, \mathrm{Ti}=1.56 \%$, providing the maximum ultimate strength $\sigma_{b}=391 \mathrm{MPa}$

$-\mathrm{C}=2.78 \%, \mathrm{C}_{e q}=3.14 \%, \mathrm{Ti}=1.61 \%$, providing the maximum wear resistance coefficient $K_{w r}=12 \%$.

It has been established that ensuring the optimal chemical composition in terms of ultimate strength also ensures the optimal wear resistance coefficient, which allows to assign the following range in terms of chemical composition: $\mathrm{C}=(2.78-2.94) \%, \mathrm{C}_{e q}=(3.14-3.3) \%, \mathrm{Ti}=(1.56-1.61) \%$ if it is necessary to simultaneously satisfy both optimality conditions.

In the case of priority of the strength criterion, the calculated optimal chemical composition makes it possible to reduce the weight and size characteristics of the mixing units of the mixers.

The obtained mathematical model can be used in two ways: design and operational. The first allows designers to prescribe the optimal chemical composition of cast iron for the blades according to the criterion of maximum strength, which must be provided at the stage of supply of the blades. The second allows to choose the batch of supplied blades that meets the specified operational requirements for strength and wear resistance. 


\section{References}

[1] Petrishin, G. V., Bystrenkov, V. M., Odarchenko, V. I. (2019). Method of providing wear-resistance of the blades of paddle mixers. Litiyo i Metallurgiya (FOUNDRY PRODUCTION AND METALLURGY), 2, 32-35. doi: https://oi.org/10.21122/ 1683-6065-2019-2-32-35

[2] Golub, G., Myhailovych, Y., Achkevych, O., Chuba, V. (2019). Optimization of angular velocity of drum mixers. EasternEuropean Journal of Enterprise Technologies, 3 (7 (99)), 64-72. doi: https://doi.org/10.15587/1729-4061.2019.166944

[3] Shushpannikov, A., Borodulin, D., Ivanets, V., Sukhorukov, D. (2015). Intensification of bulk material mixing in new designs of drum, vibratory and centrifugal mixers. Foods and Raw Materials, 3 (1), 62-69. doi: https://doi.org/10.12737/11239

[4] Hassanpour, A., Tan, H., Bayly, A., Gopalkrishnan, P., Ng, B., Ghadiri, M. (2011). Analysis of particle motion in a paddle mixer using Discrete Element Method (DEM). Powder Technology, 206 (1-2), 189-194. doi: https://doi.org/10.1016/ j.powtec.2010.07.025

[5] Bohl, D., Mehta, A., Santitissadeekorn, N., Bollt, E. (2011). Characterization of Mixing in a Simple Paddle Mixer Using Experimentally Derived Velocity Fields. Journal of Fluids Engineering, 133 (6). doi: https://doi.org/10.1115/1.4004086

[6] Gao, W., Liu, L., Liao, Z., Chen, S., Zang, M., Tan, Y. (2019). Discrete element analysis of the particle mixing performance in a ribbon mixer with a double U-shaped vessel. Granular Matter, 21 (1). doi: https://doi.org/10.1007/s10035-018-0864-4

[7] Li, S., Kajiwara, S., Sakai, M. (2021). Numerical investigation on the mixing mechanism in a cross-torus paddle mixer using the DEM-CFD method. Powder Technology, 377, 89-102. doi: https://doi.org/10.1016/j.powtec.2020.08.085

[8] Zaselskiy, V., Shved, S., Shepelenko, M., Suslo, N. (2020). Modeling the horizontal movement of bulk material in the system «conveyor - rotary mixer.» E3S Web of Conferences, 166, 06008. doi: https://doi.org/10.1051/e3sconf/202016606008

[9] Reigel, M. M., Fowley, M. D., Pickenheim, B. R. (2012). Evaluation Of Saltstone Mixer Paddle Configuration For Improved Wear Resistance. United States. doi: https://doi.org/10.2172/1052403

[10] Krasnov, I. N., Filin, V. M., Globin, A. N., Ladygin, E. A. (2014). Proizvodstvo kombikormov v usloviyah lichnyh podsobnyh i fermerskih hozyaystv. Zernograd, 228. Available at: http://xn--80aaak3h.xn--plai/files/OPOP/m2014krasnov.pdf

[11] Mohanad, M. K., Kostyk, V., Domin, D., Kostyk, K. (2016). Modeling of the case depth and surface hardness of steel during ion nitriding. Eastern-European Journal of Enterprise Technologies, 2 (5 (80)), 45-49. doi: https://doi.org/10.15587/ 1729-4061.2016.65454

[12] Kostyk, K. (2015). Development of the high-speed boriding technology of alloy steel. Eastern-European Journal of Enterprise Technologies, 6 (11 (78)), 8-15. doi: https://doi.org/10.15587/1729-4061.2015.55015

[13] Demin, D. A., Pelikh, V. F., Ponomarenko, O. I. (1995). Optimization of the method of adjustment of chemical composition of flake graphite iron. Litejnoe Proizvodstvo, 7-8, 42-43.

[14] Demin, D. A., Pelikh, V. F., Ponomarenko, O. I. (1998). Complex alloying of grey cast iron. Litejnoe Proizvodstvo, $10,18-19$.

[15] Demin, D. A. (1998). Change in cast iron's chemical composition in inoculation with a Si-V-Mn master alloy. Litejnoe Proizvodstvo, 6, 35 .

[16] Emelyushin, A. N. (2000). Vliyanie titana i bora na iznosostoykost' chuguna prednaznachennogo dlya mehanicheskoy obrabotki nemetallicheskih materialov instrumenta iz hromistyh chugunov. Izvestiya vysshih uchebnyh zavedeniy. Chernaya metallurgiya, 2, 28-29.

[17] Kontorov, B. M., Kunin, N. M. (1960). Iznosostoykie belye chuguny, legirovany borom i titanom. Liteynoe proizvodstvo, 4.

[18] Trauzedel', D., Shlyukeber, D., Donbah, F. (2003). Realizatsiya spetsial'nyh tehnologicheskih i metallurgicheskih zadach $\mathrm{v}$ induktsionnyh pechah sredney chastoty. Liteyschik Rossii, 5, 20-23.

[19] Fourlakidis, V., Diószegi, A. (2014). A generic model to predict the ultimate tensile strength in pearlitic lamellar graphite iron. Materials Science and Engineering: A, 618, 161-167. doi: https://doi.org/10.1016/j.msea.2014.08.061

[20] Endo, M., Yanase, K. (2014). Effects of small defects, matrix structures and loading conditions on the fatigue strength of ductile cast irons. Theoretical and Applied Fracture Mechanics, 69, 34-43. doi: https://doi.org/10.1016/j.tafmec. 2013.12.005

[21] Cheng, Y., Huang, F., Li, W., Liu, R., Li, G., Wei, J. (2016). Test research on the effects of mechanochemically activated iron tailings on the compressive strength of concrete. Construction and Building Materials, 118, 164-170. doi: https:// doi.org/10.1016/j.conbuildmat.2016.05.020

[22] Demin, D. (2020). Constructing the parametric failure function of the temperature control system of induction crucible furnaces. EUREKA: Physics and Engineering, 6, 19-32. doi: https://doi.org/10.21303/2461-4262.2020.001489

[23] Demin, D. (2017). Strength analysis of lamellar graphite cast iron in the «carbon (C) - carbon equivalent (Ceq)» factor space in the range of $\mathrm{C}=(3,425-3,563) \%$ and $\mathrm{C}_{e q}=(4,214-4,372) \%$. Technology Audit and Production Reserves, 1 (1 (33)), $24-32$. doi: https://doi.org/10.15587/2312-8372.2017.93178 
[24] Domin, D. (2013). Artificial orthogonalization in searching of optimal control of technological processes under uncertainty conditions. Eastern-European Journal of Enterprise Technologies, 5 (9(65)), 45-53. doi: https://doi.org/10.15587/ 1729-4061.2013.18452

[25] Vasenko, Yu. A. (2011). Wear resistance of titanium doped simulation of iron on the data passive experiment. Technology Audit and Production Reserves, 2 (2 (2)), 3-8. doi: https://doi.org/10.15587/2312-8372.2011.4858

[26] Vasenko, Yu. A. (2012). Technology for improved wear iron. Technology Audit and Production Reserves, 1 (1 (3)), $17-21$. doi: https://doi.org/10.15587/2312-8372.2012.4870

Received date 17.02.2021

Accepted date 20.04.2021

Published date 31.05.2021
(C) The Author(s) 2021

This is an open access article under the Creative Commons CC BY license

How to cite: Kharchenko, S., Barsuk, A., Karimova, N., Nanka, A., Pelypenko, Y., Shevtsov, V., Morozov, I., Morozov, V. (2021). Mathematical model of the mechanical properties of Ti-alloyed hypoeutectic cast iron for mixer blades. EUREKA: Physics and Engineering, 3, 99-110. doi: https://doi.org/10.21303/2461-4262.2021.001830 